\title{
Dielectric and Piezoelectric Studies of Dysprosium Doped BZT-BCNT Perovskite Ceramic System for Sensors and Actuators Applications
}

\section{Koduri Ramam}

Universidad de Concepcion Facultad de Ingenieria

\section{Srivathsava Surabhi}

Universidad de Concepcion Facultad de Ingenieria

Gurumurthy Sangam ( $\nabla$ gurumurthy.s.c@gmail.com )

Manipal Institute of Technology https://orcid.org/0000-0002-0721-0858

\section{Shilpa P M}

Manipal Institute of Technology

\section{Bindu K}

Indian Institute of Science

\section{Ravikirana .}

SRMIST: SRM Institute of Science and Technology

Shridhar Mundinamani

Siddaganga Institute of Technology

\section{Research Article}

Keywords: Perovskite, BZT-BCNT, Dy-doping, Dielectric and Piezoelectric Studies, Ceramics, Sensors and Actuators

Posted Date: March 10th, 2021

DOI: https://doi.org/10.21203/rs.3.rs-291438/v1

License: (c) (1) This work is licensed under a Creative Commons Attribution 4.0 International License. Read Full License 


\section{Abstract}

Perovskite structured Dy doped BZT-BCNT system has been investigated with variation of Dy doping through the solid-state reaction method. X-ray diffraction (XRD) and microscopic studies confirm the results in the rhombohedral stoichiometry without any secondary phases, and uniform grain growth, respectively. Tolerance factor and electronegativity also confirm the presence of Dy doping in BZT-BCNT ceramic system with a stable rhombohedral crystallinity forming vacancy sites for oxygen ions. Optimum piezoelectric properties in non-Pb piezoelectric ceramic systems were obtained due to trivalent donor Dy doping at A-site and pentavalent donor $\mathrm{Nb}$ at $\mathrm{B}$-site are possible members for actuator and energy harvesters. Dielectric and piezoelectric studies signifying the rhombohedral perovskite behavior of this lead-free ceramic system confess that the proposed investigation could yield further potential piezoelectric sensors and actuators applicative futuristic studies.

\section{Introduction}

Piezoceramics engrosses the polycrystalline materials of perovskite form that are being explored in the contemporary times to explicate the Lead-free alternatives [1-3] with high dielectric constants [4], and piezoelectric (PE) response [5]. These materials are widely employed in various electronic devices due to their promising functional, structure, and microstructure (phase, lattice parameters, density, and grain size) properties that can be tailored through A-site or B-site engineering by soft or hard dopants, respectively $[6,7]$. However, the efficacy of the system is dependent on the versatility of the sample fabrication, shape, sintering temperature, and dopant [1, 8-11]. Additionally, it is necessary to articulate the precise polarization rotation without having to overcome the large energy barrier [12-14] over the tetragonal $(P 4 \mathrm{~mm})$, and rhombohedral $(R 3 \mathrm{~m})$ phases at phase transition region where the orthorhombic $(A m m 2)$ and cubic $(P m 3 m)$ phases also coexist $[15,16]$. (i) Perovskite $\left(\mathrm{ABO}_{3}\right)$ structured-titanates [17], (ii) Tungsten bronze $\left(\mathrm{AB}_{2} \mathrm{O}_{6}\right)$ structured-niobates/tungstates [18], and (iii) Bismuth layer structured-oxides (BLSO) established by Aurivillius $\left(\mathrm{A}_{4} \mathrm{~B}_{3} \mathrm{O}_{12}\right)$ family [19] possess adequate $\mathrm{PE}$ properties.

The dielectric and PE properties of the sintered ceramic powder are attributed to the volatile and precarious nature of the dopants, conjoining with the sintering conditions, microstructural, temperature dependent rhombohedral-tetragonal phase transition, surfactant effect on grain size, and composition ratios [20-22]. They are usually accounted for in terms of dielectric loss, tolerance factors, and electronegativity of the system. Enhanced PE coefficients are realized from the crystallinity and phase convergence nature of piezoceramic materials such as Barium Titanate $\left(\mathrm{BaTiO}_{3}\right.$ or $\left.\mathrm{BT}\right)$, Barium Potassium Niobate $\left(\mathrm{Ba}_{0.5} \mathrm{~K}_{0.5} \mathrm{NbO}_{6}\right.$ or $\left.\mathrm{BKN}\right)$, Bismuth Potassium Titanate $\left(\mathrm{Bi}_{0.5} \mathrm{~K}_{0.5} \mathrm{TiO}_{3}\right.$ or $\left.\mathrm{BiKT}\right)$ and their modified compositions [23]. Notably, the electrical and mechanical energies of Barium-ZirconiumTitanate-Barium-Calcium-Titanate (BZT-BCT) is highly tunable [28-31] compared to the single phase $\mathrm{BaTiO}_{3}$ owing to its binary-pseudo ferroelectric system [32]. The morphotropic phase boundary (MPB) separates the rhombohedral (Zr-rich near BZT site) and tetragonal (Ti-rich near BCT site) phases. In 
summary, the dopants of soft and hard ceramics in Lead-free systems play a vital role in evincing the PE properties leveraging electronic structure and high polarizability [33].

Soft [34] and hard [35] electroceramics are constituted by doping donor (at A-site) and acceptor (at B-site) cations of similar/(higher, and lower) ionic radii, respectively. The soft ceramics hold good for sensing and actuating applications [27], while the hard ones are principally used in high voltage, mechanical loads, and power applications [36]. The effect of modified composition and donor/acceptor rare-earth ions on the MPB of BZT-BCT has been explored to yield the optimal PE properties [37-44]. Nevertheless, a very few investigations were available on Nb-doped BZT-BCT [41, 43, 44] (i.e., BZT-BCNT) out of which, in particular, $\mathrm{Dy}^{3+}$ dopant system is not available to the best of our knowledge.

In this study, Dy ${ }^{3+}$ doped 0.48 (BZT)-0.52(BCNT) series, has been synthesized by a solid-state reaction method. The stoichiometric composite structure effect of BZT-BCNT in the presence of donor-Dy at A-site over rhombohedral structure is evaluated. Furthermore, the stability of that unit cell corroborated by the calculated tolerance factor and oxygen vacancy formation is verified by the calculated electronegativity. The effect of the presence of Dy at A-site, and $\mathrm{Nb}$ at B-site over microstructure and functional properties is characterized by the XRD, apparent density, dielectric, and piezoelectricity confessing the optimum PE properties of the proposed structure of non-Pb PE electroceramic system. This work prescience the capabilities of suggested material for specified prospective piezoelectric energy harvesters, multi-layer capacitors, and actuator applications.

\section{Experimental Details}

Stoichiometric composition of Dy doped BZT-BCNT is given as

$$
0.48\left[B a_{1-x} D y_{x}\left(Z r_{0.28} T i_{\left(0.72-\left(\frac{x}{4}\right)\right)}\right) O_{3}\right]-0.52\left[\left(B a_{0.72} C a_{0.28}\right)\left(N b_{0.05} T i_{0.9375}\right) O_{3}\right]
$$

where the samples were synthesized by conventional solid-state reaction route varying the Dy concentration ( $\mathrm{x}$ ) as $0,0.2,0.4,0.6,0.8,1 \mathrm{~mol} \%$. Analytical reagent grade ( $99.99 \%$ purity) starting materials $\mathrm{BaCO}_{3}, \mathrm{Dy}_{2} \mathrm{O}_{3}, \mathrm{ZrO}_{2}, \mathrm{TiO}_{2}, \mathrm{CaCO}_{3}$ and $\mathrm{Nb}_{2} \mathrm{O}_{5}$ (Sigma Aldrich, USA, and Germany) were mixed according to the stoichiometric formula (Table 1), and ball-milled these respective batch systems by using zirconia balls and ethanol in a polyethylene jar for $12 \mathrm{~h}$. These ball-milled powders were filtered and dried at $100^{\circ} \mathrm{C}$ for $24 \mathrm{~h}$, followed by calcination at $1150^{\circ} \mathrm{C}$ for $4 \mathrm{~h}$. The set powders were ball-milled by using zirconia balls and ethanol in a polyethylene jar for $12 \mathrm{~h}$ to obtain agglomerate-free powders that were filtered and dried at $100^{\circ} \mathrm{C}$ for $24 \mathrm{~h}$. The batch calcined powders were mixed with $5 \mathrm{wt} \%$ Polyvinyl Alcohol (PVA) binder, and compacted into pellets (with $12 \mathrm{~mm}$ in diameter and 2-3 $\mathrm{mm}$ in thickness by using a steel-die and conventional hydraulic press with a uniaxial pressure of $700-900 \mathrm{~kg} / \mathrm{cm}^{2}$ ), and sintered the respective green bodies at $1450^{\circ} \mathrm{C}$ for $3 \mathrm{~h}$ with a heating rate of $5^{\circ} \mathrm{C} / \mathrm{min}$, and after the sintering process, the samples were cooled to room temperature in the furnace. Dy doped BZT-BCNT 
powder ceramic systems were analyzed by using X-ray diffraction (XRD) with a Bruker Endeavor X-ray diffractometer model D4/MAX-Bat at a scanning rate of $0.02 \%$ min over a range of Bragg angles $2 \theta$ between 20 and $70^{\circ}$. The apparent densities of the respective sintered samples were measured through the Archimedes method. As sintered ceramic surfaces were analyzed with scanning electron microscopy (SEM; JEOL model JSM 840A). An air-dry silver paste was applied on the polished pellet surfaces to form the electrodes. The electrode samples were characterized for dielectric constant $(\varepsilon)$, and dissipation factor (tan $\delta$ ) using a 1260A Impedance Analyzer. The samples were electrically poled in a silicon oil bath at $100^{\circ} \mathrm{C}$ by applying a dc field of $20 \mathrm{kV} / \mathrm{cm}$. After aging for 1 day, the poled samples were characterized for piezoelectric properties by using a Berlincourt piezo-d-meter.

\section{Results And Discussion}

\subsection{X-ray Diffraction}

Fig. 1(a) shows the powder XRD patterns of Dy doped 0.48BZT-0.52BCNT ceramics. The XRD peaks were indexed to a perovskite-type of rhombohedral structure, which shows a single rhombohedral phase as can be evidenced in the BZT-BCT phase diagram [47]. XRD patterns show sharp crystalline peaks that show the Dy diffusion in the BZT-BCNT lattice to form a solid-solution with the single-phase rhombohedral perovskite structure and no secondary phases are found that can be confessed by the tolerance factor in section 3.2. However, several reports confirm the rhombohedral-tetragonal phase transition with the variation in BZT:BCT ratio, and/or dopant modifications at MPB [48-50]. To verify, we have plotted the enlarged XRD peaks for (220), (101), and (200) planes as shown in Figs. 1(b-d), respectively. The absence of deconvolution in the planes also supports the clear existence of rhombohedral crystallinity for Dy doped BZT-BCNT. It is well known that the phase genesis and evolution from oxide precursors obtained by solid-state reaction method is temperature dependent. XRD results indicate the formation of rhombohedral symmetry throughout the series attesting the $\mathrm{Dy}^{3+}$ ions at A-site and $\mathrm{Nb}^{5+}$ ions at B-site resulting in the optimum diffused solid solutions into the BZT-BCT lattice, respectively. The compositional stoichiometry could be achieved due to the calcination and sintering process. The substitution of $\mathrm{Ba}^{2+}$ by trivalent $\mathrm{Dy}^{3+}$ at A-site in $\mathrm{BZT}$ lattice and pentavalent $\mathrm{Nb}^{5+}$ at $\mathrm{B}$-site in BCT lattice that has a deep effect on the structural and functional properties of the electroceramic system.

The rhombohedrality is justified by the intensified sharp peaks as the Dy concentration increases, in which the $\mathrm{Dy}^{3+}$ ions substitute $\mathrm{Ba}^{2+}$ and create vacancies at B-site. BZT phase (either tetragonal, orthorhombic, rhombohedral, or cubic symmetry) depends upon the BZT:BCT ratio in the binary system. The Dy-doping enhanced the rhombohedrality showing a predominant single rhombohedral phase. Furthermore, the diffraction peaks shift to the lower diffraction angles, signifying the stable large donor trivalent ions $(r>0.94 \AA)$ would occupy A-site while the small donor trivalent ions $(r<0.87 \AA)$ positioned at B-site, and the rest $(0.87 \AA<r<0.94 \AA)$ could possibly occupy A-site or B-site [51].

\subsection{Tolerance Factor}


The tolerance factor (Table 2) measures the stability of the perovskite unit cell of the ABO3 configuration. According to Goldschmidt, the ionic radii in $\mathrm{ABO}_{3}$ must fulfill the following categories: (i) the most stable structure is tetragonal $(t \geq 1)$ (ii) cubic $(t \approx 1)$, and (iii) rhombohedral or orthorhombic symmetries $(t<1)$, respectively $[48-50,52]$.

$$
t=\frac{r_{A}+r_{O}}{\sqrt{2}\left(r_{A}+r_{O}\right)}
$$

Where $t$ is the tolerance factor, $r_{A}$ is the ionic radii of the cations at A-site, $r_{B}$ is the ionic radii of cations at $\mathrm{B}$-site, and $\mathrm{r}_{\mathrm{O}}$ is the ionic radii of the oxygen at respective sites in the perovskite unit cell. Tolerance factor values are tabulated in table 2 . The tolerance factor is ranged in rhombohedral symmetry, and the rhomobhedrality is enhanced with Dy doping. It is well known that the trivalent ions could occupy $B-s i t e(r$ $<0.87 \AA)$ or A-site $(r>0.94 \AA)$, respectively. Dy ${ }^{3+}(r=1.083 \AA)$ substitutes $\mathrm{Ba}^{2+}(r=1.61 \AA)$, predominantly enhancing the rhombohedrality in the lattice. Furthermore, no secondary phases are evidenced from the XRD studies. Hence, it confirms the formation of stable rhombohedral (R3m) perovskite structure.

\subsection{Electronegativity}

Furthermore, the averaged electronegativity difference $(e)$ is an added significant parameter to weigh the stability and bonding in the perovskite.

$$
\mathrm{e}=\frac{\left(\chi_{\mathrm{A}}-\chi_{\mathrm{o}}\right)+\left(\chi_{\mathrm{B}}-\chi_{\mathrm{o}}\right)}{2}
$$

where are $\chi_{A}, \chi_{B}$, and $\chi_{0}$ the respective electronegativities of $A$-site, $B$-site cations and $\mathrm{O}^{2-}$ anions, respectively in the perovskite unit cell. It is evident from table 2 that there is no distortion noticed in rhombohedral Dy doped BZT-BCNT structure. The e of Dy doped BZT-BCNT ceramics equation can be written as

$$
\mathrm{e}=\frac{\left\{\begin{array}{c}
{\left[\left(0.48(1-y) \chi_{B a-O}+y \chi_{D y-O}\right)+0.52\left(0.72 \chi_{B a-O}+0.28 \chi_{C a-O}\right)\right]+} \\
{\left[\begin{array}{c}
\left.\left(0.48\left(0.28 \chi_{Z r-O}\right)+\left(0.72-(X / 4) \chi_{T i-O}\right)\right)+\right] \\
\left(0.52\left(0.05 \chi_{N b-O}+(1-(5 / 4) * y) \chi_{T i-O}\right)\right)
\end{array}\right]}
\end{array}\right\}}{8}
$$

Electronegativity (Table 2) evaluates the oxygen vacancies and shows the tendency of the atomic bonding depending on the electron-ionization energy. It is well known that the lanthanides tend to replace 
$\mathrm{Ba}^{2+}$ rather than $\mathrm{Ti}^{4+}$ and make it a donor or acceptor doping depending on its ionic radii in the unit cell. Electronegativity is the difference between the sum of cations and anions that reflects the tendency of the bonded atom to attract shared electrons. Therefore, the greater the electronegativity, the greater the attraction of electrons, and the nature of bond is determined by the differences in the electronegativity. Electronegativity is caused as the chemical bonding between the atoms that are formed which could be positive or negative electrons that determines the bond type i.e., ionic, covalent, or metallic. If the electronegativity is below 0.5 , then the bond is said to be a non-polar covalent. If the electronegativity is between 0.5 and 2.1 , it is said to be a polar covalent. If the electronegativity is more than 2.1 , it is said to be an ionic in nature. The electronegativity of Dy doped BZT-BCNT is in the range of 0.6354 to 0.6316 , which attests the polar covalent bonding. The multiple cations in the BZT-BCNT rhombohedral perovskite ceramic system resulted in sharing of $\mathrm{Dy}^{3+}$ and $\mathrm{Ca}^{2+}$ ions in the place of $\mathrm{Ba}^{2+}(\mathrm{A}$-sites $)$ at BZT and BCNT, respectively, also, $\mathrm{Nb}^{5+}$ replacing $\mathrm{Ti}^{4+}$ at $\mathrm{B}$-site of $\mathrm{BCT}$ resulted in a polar covalent bonding of the material, which can stabilize the piezoelectric (PE) perovskite phase [53, 54].

\subsection{Scanning Electron Microscopy (SEM)}

The microstructure of Dy doped BZT-BCNT ceramics is presented in fig. 2(a-c) for the $0.2,0.8,1 \mathrm{~mol} \%$. It is evident that, small concentration of pentavalent $\mathrm{Nb}$ enhances grain growth, while Dy doping supported the domain reorientation in aligning and densifying the coarse grains. The oxygen vacancies supported the charge balance in the BZT-BCNT ceramic system due to the sintering process that in turn enhanced the density. The sintering process (temperature and time) caused enhancement in grain growth with the increase in Dy content. The homogeneously dense grains attested by SEM influenced the net polarization up to $0.8 \mathrm{~mol} \%$ and thereafter attained saturation.

\subsection{Density studies}

Fig. 3 depicts the variation of density with Dy concentration for sintered ceramic samples. It is well known that the composition of the materials dictates the optimum sintering temperature [55, 56]. Initially, the density intensifies with increase in Dy concentration up to $0.8 \mathrm{~mol} \%$ and reduces thereafter. One of the prominent reasons for lowering the density is the incomplete removal of pore or trapped pore present in the grain. Further, the decrease in density for $1 \mathrm{~mol} \%$ suggests the limit of addition of dopant to BZTBCNT ceramics. Therefore, the density study results indicate that the sintering temperature of $1450{ }^{\circ} \mathrm{C}$ is optimum for $0.8 \mathrm{~mol} \%$.

\subsection{Dielectric studies}

Fig. 4 shows the dielectric properties of Dy doped 0.48BZT-0.52BCNT ceramics characterized at $1 \mathrm{kHz}$. It is observed in Fig. 4(a) that the dielectric constant of the perovskite structured BZT-BCNT ceramic system increases gradually with temperature and reaches dielectric maximum at $98{ }^{\circ} \mathrm{C}$ which is the Curie transition temperature $\left(T_{c}\right)$, and with additional rise in temperature the dielectric constant declines for pure. It can be witnessed that for Dy doping (0.2 to $1.0 \mathrm{~mol} \%)$ of BZT-BCNT exhibited a similar trend in 
this ceramic system. In addition to that, it is observed that maximum dielectric constant is achieved at a lower temperature for Dy doped BZT-BCNT systems up to $0.8 \mathrm{~mol} \%$, compared to the pure sample and thereafter the trend reverses. The curie transition temperature in the series has witnessed a similar trend. There are many factors that contribute to the high dielectric constant like, modifications in the grain size and grain boundary, change in density, release of internal stress, and the defect and domain wall motion [57].

Fig. $4 \mathrm{~b}$ shows the variation of dielectric loss of Dy doped BZT-BCNT ceramics with temperature. It is detected that at room temperature the dielectric loss decreases gradually with rising Dy doping up to 0.8 mol\% (optimum) and thereafter increases at room temperature. Furthermore, it is seen that with the increase in temperature, the dielectric loss decreases and reaches minimum at $\sim 80^{0} \mathrm{C}$ for all the Dy doping BZT-BCNT ceramic systems, which might be owing to the manifold cationic arrangements or saturation in the perovskite ceramic system.

In the rhombohedral symmetry, as Dy doping supported the space charge polarization due to the donor $\mathrm{Dy}^{3+}$ dopant in BZT lattice and pentavalent $\mathrm{Nb}^{5+}$ in the BCT lattice by balancing the charge and oxygen vacancies in the present system $[58,59]$. The polarization of a dielectric material is influenced by the dipolar, electronic, ionic, and interfacial interactions in the unit cell. The incorporation of Dy in the BZT and $\mathrm{Nb}$ in BCT drastically influenced the polarization in attaining optimum electrical properties that resulted in the increased dielectric constant. The dielectric constant $\left(\mathrm{e}_{\mathrm{RT}}=1342\right)$ at room temperature, dielectric maximum $\left(\mathrm{e}_{\mathrm{Tc}}=10667\right)$ at the Curie Temperature $\mathrm{T}_{\mathrm{C}}\left(81^{\circ} \mathrm{C}\right)$ is found to be optimum for $0.8 \mathrm{~mol} \%$ at the frequency of $1 \mathrm{kHz}$. It was reported that there was a mixed trend of the dielectric loss and Curie temperature with Dy incorporation in $\mathrm{BaTiO}_{3}$ [60], similarly, we confirm the same trend in this perovskite BZT-BCNT ceramic system.

\subsection{Piezoelectric studies}

Fig. 5 shows the piezoelectric coefficient $d_{33}$ as a function of Dy concentration. It can be observed that with the increasing Dy concentration, the piezoelectric constant $d_{33}$ increases up to $0.8 \mathrm{~mol} \%$ and attains a maximum value $368 \mathrm{pC} / \mathrm{N}$ and then decreases sharply with further Dy concentration. It is believed that the observed high piezoelectric properties should be ascribed to the phase, polarization due to multiple cations, dopants, enhanced grain size (possible net polarization from respective domains), dense ceramics [61]. Further, lattice distortion provoked by Dy doping content may be advantageous to ferroelectric domain reorientation during poling process have some bearing on the improvement of piezoelectric properties. However, with the increasing of Dy content to $1 \mathrm{~mol} \%$, Dy ions should occupy the A-site of $\mathrm{Ba}^{2+}$, which might cause deformation in the perovskite $\mathrm{ABO}_{3}$ lattice to make a phase transition completed, resulting in a reduction of piezoelectric coefficient $d_{33}[9,61]$. This shows that a proper addition of Dy induces a more significant piezoelectric activity in these perovskites, which can be chiefly ascribed to nature of the dopant and its content, the densification and grain morphology of the ceramic system. 


\section{Conclusion}

We report the perovskite structured Dy doped BZT-BCNT system resulting in the rhombohedral stoichiometry without any secondary phases being observed. Superior net polarization due to homogeneous dense coarse grains, which not only enhanced the electrical properties but also favoring the piezoelectric applicative investigation while exhibiting the rhombohedral phase of Dy doped BZTBCNT ceramic system. Tolerance factor and electronegativity confirm the stable rhombohedral crystallinity in forming vacancy sites by oxygen ions and polar covalent bonding in the perovskite phase, respectively. Optimum dielectric and piezoelectric properties are observed at $0.8 \mathrm{~mol} \%$ due to donor Dy ${ }^{3+}$ doping at $\mathrm{A}$-site and donor $\mathrm{Nb}^{5+}$ at B-site in the non-Pb perovskite structured (BZT-BCNT) ceramic system. The obtained results could be helpful in developing sensors and actuators.

\section{Declarations}

\section{Acknowledgements \& Funding Information}

This work is supported by the research grants funded by Fondecyt (Programa Fondo Nacional de Desarrollo Científico y Tecnológico (FONDECYT) de la Agencia Nacional de Investigación y Desarrollo, Chile) Regular ( $\left.\mathrm{N}^{\circ} 1110583\right)$, Fondecyt Post-doctoral ( $\left.\mathrm{N}^{\circ} 3200832\right)$, Proyecto FONDEF, CONICYT, Chile. (ID15I10312), Chile, and CORFO project (N 15IPPID-45708). The authors would like to sincerely thank the University of Concepcion, Chile and Andhra University, India for their enormous support and facilities provided. This work is also supported by the Manipal Academy of Higher Education (MIT-2017, 2020), Karnataka, India. The authors also like to be grateful towards the efforts offered by Mr. Ranganathan, Mr. Krishnamurthy and Ms. C. N. Devi for their technical assistance and valuable suggestions extended during this work.

\section{Conflicts of interest/Competing interests}

Authors declare no conflict/competing interests as per the guidelines of the journal.

\section{References}

[1] M.C. Ehmke, J. Glaum, M. Hoffman, J.E. Blendell, K.J. Bowman (2013) In situ X-ray diffraction of biased ferroelastic switching in tetragonal lead-free (1-x) $\mathrm{Ba}\left(\mathrm{Zr}_{0.2} \mathrm{Ti}_{0.8}\right) \mathrm{O}_{3}-\mathrm{x}\left(\mathrm{Ba}_{0.7} \mathrm{Ca}_{0.3}\right) \mathrm{TiO}_{3}$ piezoelectrics. J. Am. Ceram. Soc 2913:2920- 96 https://doi.org/10.1111/jace.12424

[2] D. Fu, M. Itoh, S.Y. Koshihara (2009) Dielectric, ferroelectric, and piezoelectric behaviors of $\mathrm{AgNbO}_{3}$ $\mathrm{KNbO}_{3}$ solid solution. J. Appl. Phys 104104- 106. https://doi.org/10.1063/1.3259410

[3] Y. Yoneda, S. Kohara, H. Nagata, D. Fu, T. Takenaka (2014) Local Structure Analysis of Nb-related Perovskite Materials. Trans. Mat. Res. Soc Japan 455:458- 39. https://doi.org/10.14723/tmrsj.39.455 
[4] G. Arlt, D. Hennings, G. De With (1985) Dielectric properties of fine-grained barium titanate ceramics. J. Appl. Phys 1619-58. https://doi.org/10.1063/1.3360251

[5] M. Acosta, N. Novak, V. Rojas, S. Patel, R. Vaish, J. Koruza, G.A. Rossetti, J. Rödel (2017) $\mathrm{BaTiO}_{3}$-based piezoelectrics: Fundamentals, current status, and perspectives. Appl. Phys. Rev 041305-

4. https://doi.org/10.1063/1.4990046

[6] L. Wang, W. Bai, X. Zhao, Y. Ding, S. Wu, P. Zheng, P. Li, J. Zhai (2020) Influences of rare earth site engineering on piezoelectric and electromechanical response of $\left(\mathrm{Ba}_{0.85} \mathrm{Ca}_{0.15}\right)\left(\mathrm{Zr}_{0.1} \mathrm{Ti}_{0.9}\right) \mathrm{O}_{3}$ lead-free ceramics. J Mater Sci: Mater Electron 31, 6560-6573. https://doi.org/10.1007/s10854-020-03212-1

[7] N. Jiang, L. Luo, F. Lei, Q. Zheng, C. Xu, J. Liao, D. Lin (2015) Enhanced piezoelectricity and photoluminescence in Dy-modified $0.94\left(\mathrm{Bi}_{1-x} \mathrm{Dy}{ }_{x}\right)_{0.5} \mathrm{Na}_{0.5} \mathrm{TiO}_{3}-0.06 \mathrm{BaTiO}_{3}$ lead-free multifunctional ceramics. J Mater Sci: Mater Electron 26, 4981-4987. https://doi.org/10.1007/s10854-015-3010-7

[8] M. Zannen, A. Lahmar, B. Asbani, H. Khemakhem, M. El Marssi, Z. Kutnjak, M. Es Souni (2015) Electrocaloric effect and luminescence properties of lanthanide doped $\left(\mathrm{Na}_{1} /{ }_{2} \mathrm{Bi}_{1} /{ }_{2}\right) \mathrm{TiO}_{3}$ lead free materials. Appl. Phys. Lett 032905- 107. https://doi.org/10.1063/1.4927280

[9] P. Mishra, Sonia, P.Kumar(2012) Effect of sintering temperature on dielectric, piezoelectric and ferroelectric properties of BZT-BCT 50/50 ceramics. J. Alloy. Comp 210:215- 54. https://doi.org/10.1016/j.jallcom.2012.08.017

[10] V.S. Puli, D.K. Pradhan, B.C. Riggs, S. Adireddy, R.S. Katiyar, D.B. Chrisey (2014) Synthesis and characterization of lead-free ternary component BST-BCT-BZT ceramic capacitors. J. Adv. Dielect. 1450014- 4.https://doi.org/10.1142/S2010135X14500143

[11] D.A. Tuan, L.D. Vuong, V.T. Tung, N.N. Tuan, N.T. Duong(2018) Dielectric and ferroelectric characteristics of doped BZT-BCT ceramics sintered at low temperature. J. CERAM. Process RES 32:3619.

[12] M. Davis, M. Budimir, D. Damjanovic, N. Setter (2007) Rotator and extender ferroelectrics: Importance of the shear coefficient to the piezoelectric properties of domain-engineered crystals and ceramics. J. Appl. Phys 054112- 101. https://doi.org/10.1063/1.2653925

[13] W. Liu, X. Ren (2009) Large piezoelectric effect in Pb-free ceramics. Phys. Rev. Lett 257602- 103. https://doi.org/10.1103/PhysRevLett.103.257602

[14] D. Damjanovic, N. Klein, J. Li, V. Porokhonskyy(2010) What can be expected from lead-free piezoelectric materials?. Funct. Mater. Lett. 5:13-3. https://doi.org/10.1142/S1793604710000919

[15] D. Xue, J. Gao, Y. Zhou, X. Ding, J. Sun, T. Lookman, X. Ren (2015) Phase transitions and phase diagram of $\mathrm{Ba}\left(\mathrm{Zr}_{0.2} \mathrm{Ti}_{0.8}\right) \mathrm{O}_{3}-\mathrm{x}\left(\mathrm{Ba}_{0.7} \mathrm{Ca}_{0.3}\right) \mathrm{TiO}_{3} \mathrm{~Pb}$-free system by anelastic measurement. J. Appl. Phys 
[16] D.S. Keeble, F. Benabdallah, P.A. Thomas, M. Maglione, J. Kreisel (2013) Revised structural phase diagram of $\left(\mathrm{Ba}_{0.7} \mathrm{Ca}_{0.3} \mathrm{TiO}_{3}\right)-\left(\mathrm{BaZr}_{0.2} \mathrm{Ti}_{0.8} \mathrm{O}_{3}\right)$. Appl. Phys. Lett 092903-102. https://doi.org/10.1063/1.4793400

[17] Y. Xu (1991) Ferroelectric Materials and Their Application $2^{\text {nd }}$ ed, North Holand.

[18] K. Chandramouli, P. Viswarupachary, R. Koduri (2009) Pyroelectric and d.c. resistivity studies of barium strontium cerium lithium sodium niobate ceramics Ceram. - Silikaty 15:19- 53.

[19] N. Shara Sowmya, A. Srinivas, P. Saravanan, K. Venu Gopal Reddy, S. V. Kamat, J. Paul Praveen, D. Das, G. Murugesan, S. Dinesh Kumar, V. Subramanian (2018) Studies on magnetoelectric coupling in lead-free [(0.5)BCT-(0.5)BZT]-NiFe $\mathrm{O}_{4}$ laminated composites at low and EMR frequencies. J. Alloy Comp. 240:248- 743. https://doi.org/10.1016/j.jallcom.2018.01.402

[20] Z. Hanani, D. Mezzane, M. Amjoud, S. Fourcade, A.G. Razumnaya, I.A. Luk'yanchuk, M. Gouné(2019) Enhancement of dielectric properties of lead-free BCZT ferroelectric ceramics by grain size engineering. Superlattices Microstruct 109:117- 127. https:// doi.org/10.1016/j.spmi.2018.03.004

[21] Y. Bai, A. Matousek, P. Tofel, V. Bijalwan, B. Nan, H. Hughes, T.W. Button(2015) (Ba,Ca)(Zr,Ti)O 3 leadfree piezoelectric ceramics-The critical role of processing on properties. J. Eur. Ceram. Soc 3445:3456- 35. https://doi.org/10.1016/j.jeurceramsoc.2015.05.010

[22] H.L. Sun, Q.J. Zheng, Y. Wan, Y. Chen, X. Wu, K.W. Kwok, H.L.W. Chan, D.M. Lin (2015) Correlation of grain size, phase transition and piezoelectric properties in $\mathrm{Ba}_{0.85} \mathrm{Ca}_{0.15} \mathrm{Ti}_{0.90} \mathrm{Zr}_{0.1003}$ ceramics. $\mathrm{J}$ Mater Sci Mater Electron 5270:5278- 26.

[23] Y. Tian, L. Wei, X. Chao, Z. Liu, Z. Yang (2013) Phase transition behavior and large piezoelectricity near the morphotropic phase boundary of lead-free $\left(\mathrm{Ba}_{0.85} \mathrm{Ca}_{0.15}\right)\left(\mathrm{Zr}_{0.1} \mathrm{Ti}_{0.9}\right) \mathrm{O}_{3}$ ceramics J. Am. Ceram Soc 496:502- 96. 10.1111/jace.12049

[24] B. Li, J.E. Blendell, K.J. Bowman (2011) Temperature-dependent poling behavior of lead-free BZT-BCT piezoelectrics. J. Am. Ceram Soc 3192:3194- 94. 10.1111/j.1551-2916.2011.04758.x

[25] P. Sateesh, J. Omprakash, G.S. Kumar, G. Prasad (2015) Studies of phase transition and impedance behavior of $\mathrm{Ba}(\mathrm{Zr}, \mathrm{Ti}) \mathrm{O}_{3}$ ceramics. J. Adv. Dielect 1550002-5. 10.1142/S2010135X15500022

[26] Q. Chi, G. Liu, C. Zhang, Y. Cui, X. Wang, Q. Lei (2018) Microstructure and dielectric properties of BZTBCT/PVDF nanocomposites Results Phys. 391:396- 8. 10.1016/j.rinp.2017.12.052

[27] V.B. Shirokov, M. V. Talanov (2019) Phase transitions in $\mathrm{Bi}_{4} \mathrm{Ti}_{3} \mathrm{O}_{12}$. Acta Cryst. B. (2019) 978:986- 75. $10.1107 /$ S2052520619011843 
[28] K. Ramam, M. Lopez, K. Chandramouli (2009) Dielectric and piezoelectric studies of perovskitetungsten bronze structured (1-x)PLZT-xPBBiN nanoceramic composites by high-energy mechanical activation technique. J. Alloy. Comp 211:216- 488. 10.1016/j.jallcom.2009.08.082

[29] R. Koduri, M. Lopez, C. Kemburu (2011) Structural and functional properties of (1 - X)PLZT-xPBLBiN nanoceramic composites by high-energy mechanical activation technique. J. Mater. Sci. Mater. Electron 437:443- 22. doi:10.1007/s10854-010-0156-1

[30] R. Koduri, M. Lopez, K. Chandramouli (2010) Dielectric and piezoelectric studies of perovskitetungsten bronze structured (1 - X)[0.5PMN-0.5PZT]-xPBBiN nanoceramic composites by high-energy mechanical activation technique. J. Mater. Sci. Mater. Electron 932:938- 21. 10.1007/s10854-009-0020-3

[31] R. Hayati, M. Fayazi, H. Diargar, M. Kaveh, L. Tayebi (2020) Electrical and mechanical properties of BZT - xBCT lead-free piezoceramics. Int. J. Appl .Ceram. Technol 1891:1898- 17. 10.1111/ijac.13494

[32] K. Ramam, K.C. Mouli, M.J. Fornerod, A. Elena, S. Rebolledo, A. Yellapragada (2014) Core Shell Structured Multiferroic Nanocomposites for Smart Energy Harvesting: Electric Powering for Portable Electronic Devices. Int. J. Appl. Eng. Res 57:64- 14.

[33] V.S. Puli, D.K. Pradhan, B.C. Riggs, D.B. Chrisey, R.S. Katiyar, Investigations on structure, ferroelectric, piezoelectric and energy storage properties of barium calcium titanate (BCT) ceramics, J. Alloy. Comp. 584 (2014) 369-373. 10.1016/j.jallcom.2013.09.108

[34] K. Ramam, K. Chandramouli (2009) Dielectric and piezoelectric properties of combinatory effect of Asite isovalent and B-site acceptor doped PLZT ceramics. Ceram. Silikaty 189:194- 53.

[35] K. Ramam, M. Lopez (2006) Ferroelectric and piezoelectric properties of Ba modified lead zirconium titanate ceramics. J. Phys. D Appl. Phys. 4466:4471- 39. 10.1088/0022-3727/39/20/025

[36] K. Ramam, M. Lopez (2007) Effect of strontium doping on dielectric, ferroelectric and piezoelectric properties of PLZTN ceramics. Mat. Sci. Eng. B-Adv 41:47-145. 10.1016/j.mseb.2007.09.085

[37] Z. Wang, W. Li, R. Chu, J. Hao, Z. Xu, G. Li (2016) Strong luminescence and high piezoelectric properties in Pr-doped $\left(\mathrm{Ba}_{0.99} \mathrm{Ca}_{0.01}\right)\left(\mathrm{Ti}_{0.98} \mathrm{Zr}_{0.02}\right) \mathrm{O}_{3}$ multifunctional ceramics. J. Alloy. Comp 30:35- 689. 10.1016/j.jallcom.2016.07.307

[38] L. Wang, W. Bai, X. Zhao, Y. Ding, S. Wu, P. Zheng, P. Li, J. Zhai, Influences of rare earth site engineering on piezoelectric and electromechanical response of $\left(\mathrm{Ba}_{0.85} \mathrm{Ca}_{0.15}\right)\left(\mathrm{Zr}_{0.1} \mathrm{Ti}_{0.9}\right) \mathrm{O}_{3}$ lead-free ceramics, J. Mater. Sci. Mater. Electron. 31 (2020) 6560-6573. 10.1007/s10854-020-03212-1

[39] J. Shi, X. Lu, J. Shao, B. Fang, S. Zhang, Q. Du, J. Ding, X. Zhao, H. Luo (2017) Effects on structure and properties of BCZT lead-free piezoelectric ceramics by rare-earth doping. Ferroelectrics 197: 507- 186. 10.1080/00150193.2017.1283941 
[40] A. Hamza, F. Benabdallah, I. Kallel, L. Seveyrat, L. Lebrun, H. Khemakhem (2018) Effect of rare-earth substitution on the electrical properties and Raman spectroscopy of BCTZ ceramics. J. Alloy. Comp 2523:2531- 735. 10.1016/j.jallcom.2017.11.351

[41] H. Bao, C. Zhou, D. Xue, J. Gao, X. Ren (2012) A modified lead-free piezoelectric BZT-xBCT system with higher $T_{C}$. J. Phys. D Appl. Phys 465401- 43. 10.1088/0022-3727/43/46/465401

[42] R. Koduri, M. Lopez (2008) Influence of Mn on dielectric and piezoelectric properties of A-site and Bsite modified PLZT nano-ceramics for sensor and actuator applications. J. Mater. Sci. Mater. Electron 669:675- 19. 10.1007/s10854-007-9419-x

[43] K. Ramam, K. Chandramouli, P. Viswarupachary (2009) Alkali-lithium modification on rare-earthneodymium-doped barium strontium sodium niobate ceramics for dielectric and pyroelectric properties. J. Alloy. Comp 574:578- 479. 10.1016/j.jallcom.2009.01.063

[44] K. Ramam, K. Chandramouli(2011) Dielectric and piezoelectric properties of rare-earth gadolinium modified lead lanthanum zirconium niobium titanate ceramics. Ceram. Int 979:984- 37.

10.1016/j.ceramint.2010.11.016

[45] K. Ramam, M. Lopez (2008) Dielectric, ferroelectric and piezoelectric studies of neodymium-modified PLZNT ceramics for sensor and actuator applications. J. Alloy. Comp 398:403- 466. http://dx.doi.org/10.1016/j.jallcom.2007.11.055

[46] C. Zhang, Q. Bin Liu, X.Q. Huang (2013) Effect of sintering temperature on microstructure and electrical properties of (Mn, Nb)-doped BZT-BCT ceramics. Adv. Mater. Res 59:62- 820. https://doi.org/10.4028/www.scientific.net/AMR.900.119

[47] J. Gao, D. Xue, Y. Wang, D. Wang, L. Zhang, H. Wu, S. Guo, H. Bao, C. Zhou, W. Liu, S. Hou, G. Xiao, X. Ren (2011) Microstructure basis for strong piezoelectricity in Pb-free $\mathrm{Ba}\left(\mathrm{Zr}_{0.2} \mathrm{Ti}_{0.8}\right) \mathrm{O}_{3}-\left(\mathrm{Ba}_{0.7} \mathrm{Ca}_{0.3}\right) \mathrm{TiO}_{3}$ ceramics. Appl. Phys. Lett 092901- 99. https://doi.org/10.1063/1.3629784

[48] D.A. Tuan, V.T. Tung, T. Van Chuong, N.T. Tinh, N.T.M. Huong (2015) Structure, microstructure and dielectric properties of lead-free BCT-xBZT ceramics near the morphotropic phase boundary. Indian J. Pure Appl. Phys 2015- 53. http://hdl.handle.net/123456789/31600

[49] C.H. Zhang, Q.G. Chi, X.X. He, J.Q. Lin, Y. Chen, L.Z. Liu, Q.Q. Lei (2016) Microstructure and electric properties of $\mathrm{Nb}$ doping $x\left(\mathrm{Ba}_{0.7} \mathrm{Ca}_{0.3}\right) \mathrm{TiO}_{3}-(1-\mathrm{x}) \mathrm{Ba}\left(\mathrm{Zr}_{0.2} \mathrm{Ti}_{0.8}\right) \mathrm{O}_{3}$ ceramics. J. Alloy. Comp 936:940- 685 . https://doi.org/10.1016/j.jallcom.2016.06.203

[50] A.R. Jayakrishnan, K. V. Alex, A. Thomas, J.P.B. Silva, K. Kamakshi, N. Dabra, K.C. Sekhar, J. Agostinho Moreira, M.J.M. Gomes (2019) Composition-dependent xBa $\left(\mathrm{Zr}_{0.2} \mathrm{Ti}_{0.8}\right) \mathrm{O}_{3}-(1-\mathrm{x})\left(\mathrm{Ba}_{0.7} \mathrm{Ca}_{0.3}\right) \mathrm{TiO}_{3}$ bulk ceramics for high energy storage applications. Ceram. Int 5808:5818- 45. https://doi.org/10.1016/j.jallcom.2016.06.203 
[51] W. Li, J. Hao, W. Bai, Z. Xu, R. Chu, J. Zhai (2012) Enhancement of the temperature stabilities in yttrium doped $\left(\mathrm{Ba}_{0.99} \mathrm{Ca}_{0.01}\right)\left(\mathrm{Ti}_{0.98} \mathrm{Zr}_{0.02}\right) \mathrm{O}_{3}$ ceramics. J. Alloy. Comp 46:49- 531.

10.1016/j.jallcom.2012.03.110

[52] V.M. Goldschmidt (1926) Die Gesetze der Krystallochemie. Naturwissenschaften 477:485- 14. https://doi.org/10.1007/BF01507527.

[53] P.F. Zhou, B.P. Zhang, L. Zhao, L.F. Zhu (2015) Effect of LiF addition on phase structure and piezoelectric properties of $(\mathrm{Ba}, \mathrm{Ca})(\mathrm{Ti}, \mathrm{Sn}) \mathrm{O}_{3}$ ceramics sintered at low temperature. Ceram. Int 4035:404141. https://doi.org/10.1007/BF01507527

[54] S. Li, H. Nie, G. Wang, N. Liu, M. Zhou, F. Cao, X. Dong (2019) Novel AgNbO 3 -based lead-free ceramics featuring excellent pyroelectric properties for infrared detecting and energy-harvesting applications: Via antiferroelectric/ferroelectric phase-boundary design. J. Mater. Chem. C 4403:4414- 7. https://doi.org/10.1039/C9TC01014A

[55] A.N. Ahmed, H.M.M.A. Rashed (2017) Processing and characterization of calcined and sintered niobium doped barium titanate. Ferroelectrics 118:126- 506.

https://doi.org/10.1080/00150193.2017.1282285

[56] H. Hughes, D.M. Iddles, I.M. Reaney (2001), Niobate-based microwave dielectrics suitable for third generation mobile phone base stations. App. Phys. Lett 2952- 79. https://doi.org/10.1063/1.1414296

[57] S. Bhaskar Reddy, K. Prasad Rao, M.S. Ramachandra Rao (2009) Effect of La substitution on the structural and dielectric properties of $\mathrm{BaZr}_{0.1} \mathrm{Ti}_{0.9} \mathrm{O}_{3}$ ceramics. J. Alloy. Comp. 692:696- 481.

[58] K. Chandramouli, G.S. Reddy, K. Ramam (2009) Dielectric and piezoelectric properties of ceriummodified lead barium niobate ceramics. J. Alloy. Comp 609:616- 469.

https://doi.org/10.1016/j.jallcom.2008.02.022

[59] K. Ramam, M. Lopez (2008) Structural, dielectric and piezoelectric studies of (1-x)PLSZNT-xBaTiO 3 ceramics. J. Alloy. Comp 446:451- 465. https://doi.org/10.1155/2013/125634

[60] A. Kaushal, S.M. Olhero, B. Singh, R. Zamiri, V. Saravanan, J.M.F. Ferreira (2014) Successful aqueous processing of a lead free $0.5 \mathrm{Ba}\left(\mathrm{Zr}_{0.2} \mathrm{Ti}_{0.8}\right) \mathrm{O}_{3}-0.5\left(\mathrm{Ba}_{0.7} \mathrm{Ca}_{0.3}\right) \mathrm{TiO}_{3}$ piezoelectric material composition. RSC Adv 2699:27002- 4. https://doi.org/10.1039/C4RA03172E

[61] W. Li, Z. Xu, R. Chu, P. Fu, and G. Zang (2011) Temperature Stability in Dy-Doped $\left(\mathrm{Ba}_{0.99} \mathrm{Ca}_{0.01}\right)$ (Ti0.98Zr0.02) O ${ }_{3}$ Lead-Free Ceramics with High Piezoelectric Coefficient. J. Am. Ceram. Soc 3181:318394. https://doi.org/10.1111/j.1551-2916.2011.04744.x

\section{Tables}


Table 1 Stoichiometric compositions of the Dy doped BZT-BCNT ceramic system.

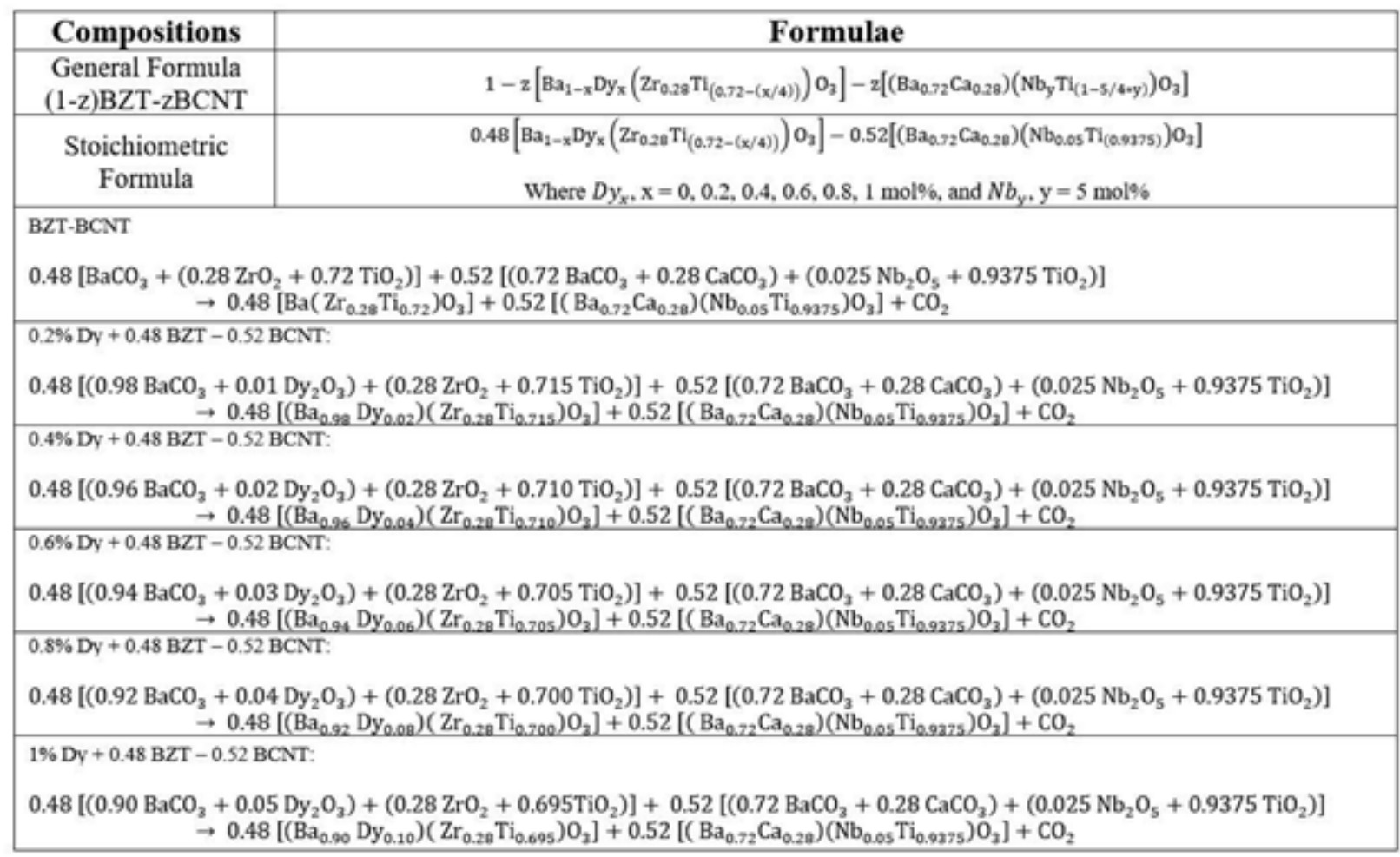

Table 2: Tolerance factor and Electronegativity of Dy doped BZT-BCNT ceramic system.

\begin{tabular}{|c|c|c|c|c|c|}
\hline Compositions & $\begin{array}{l}\text { Ionic Radii/ } \\
\text { Electronegativ } \\
\text { cations }\end{array}$ & of A-site & $\begin{array}{l}\text { Ionic Radii/ } \\
\text { Electronegativit) } \\
\text { of B-site cations }\end{array}$ & $\begin{array}{l}\text { Tolerance } \\
\text { Factor }\end{array}$ & Electronegativity \\
\hline BZT-BCNT & $\mathrm{Ba}^{2+}: 1.61 \AA$ & / 0.89 & $\mathrm{Zr}^{4+}: 0.72 \AA$ & 0.8450 & 0.6354 \\
\hline $\begin{array}{l}\text { Dy } 0.2 \mathrm{~mol} \% \\
+ \\
\text { BZT-BCNT }\end{array}$ & $\begin{array}{l}\mathrm{Dy}^{3+}: 1.083 \AA \\
\mathrm{Ca}^{2+}: 1.34 \AA\end{array}$ & $\begin{array}{l}/ 1.22 \\
/ 1.00\end{array}$ & $\begin{array}{l}\mathrm{Ti}^{4+}: 0.605 \AA \\
1.90\end{array}$ & 0.8445 & 0.6347 \\
\hline $\begin{array}{l}\text { Dy } 0.4 \mathrm{~mol} \%+ \\
\text { BZT-BCNT }\end{array}$ & $0^{3-}: 1.42 \AA$ & / 3.44 & $\begin{array}{l}\mathrm{Nb}^{5+}: 0.74 \AA \\
1.84\end{array}$ & 0.8440 & 0.6339 \\
\hline $\begin{array}{l}\text { Dy } 0.6 \mathrm{~mol} \%+ \\
\text { BZT-BCNT }\end{array}$ & & & $3.4 \dot{4}$ & 0.8435 & 0.6331 \\
\hline $\begin{array}{l}\text { Dy } 0.8 \mathrm{~mol} \%+ \\
\text { BZT-BCNT }\end{array}$ & & & & 0.8431 & 0.6324 \\
\hline $\begin{array}{l}\text { Dy } 1 \mathrm{~mol} \%+ \\
\text { BZT-BCNT }\end{array}$ & & & & 0.8426 & 0.6316 \\
\hline
\end{tabular}




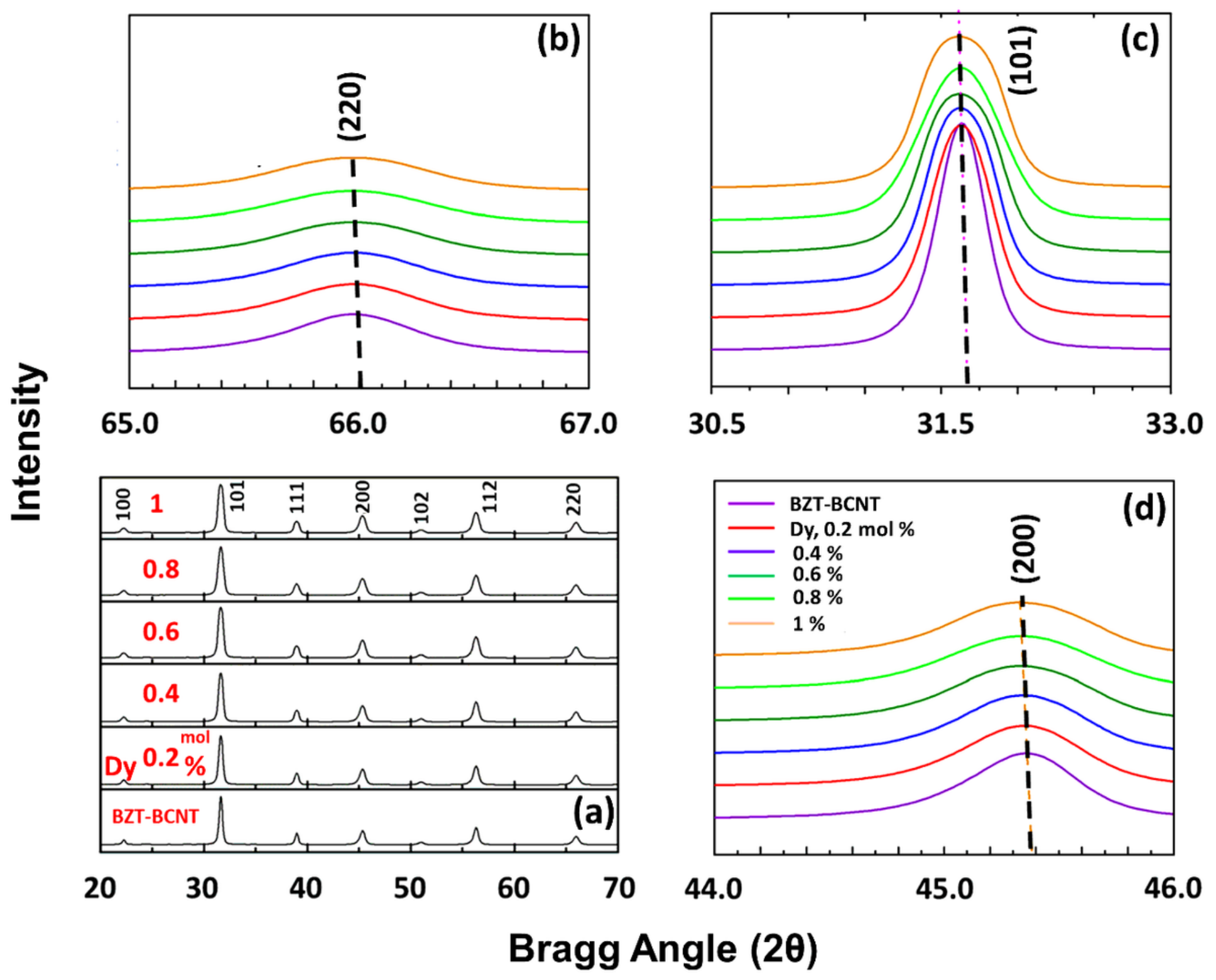

Figure 1

(a) Powder X-ray diffraction patterns of Dy doped BZT-BCNT ceramic system, (b)-(d) extended XRD scan of respective $2 \theta^{\circ}$ of Dy doped BZT-BCNT ceramic system 

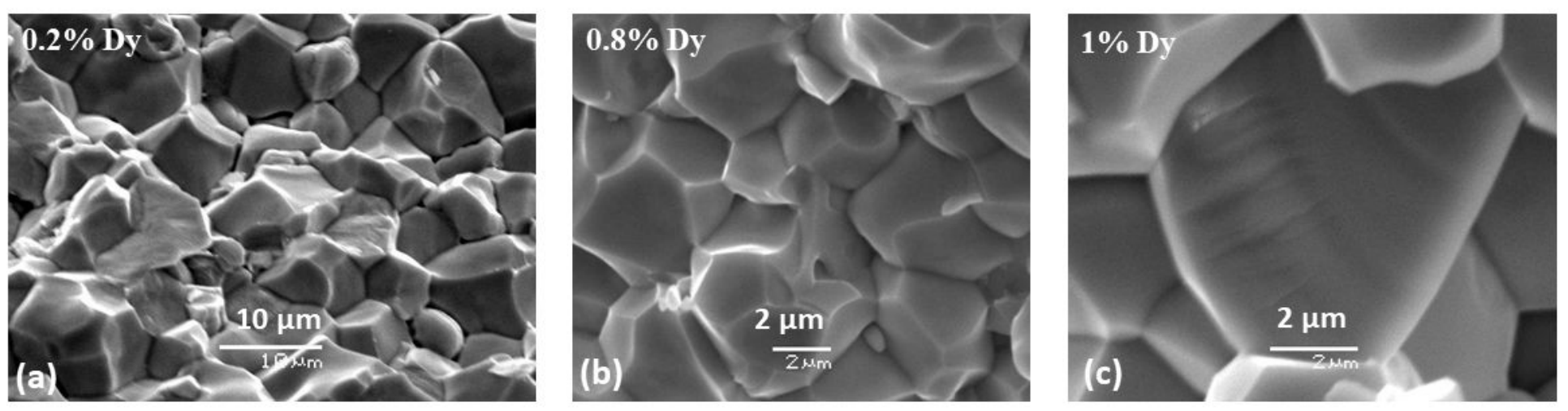

Figure 2

SEM morphological studies of (a) $0.2 \mathrm{~mol} \%$, (b) $0.8 \mathrm{~mol} \%$, (c) $1 \mathrm{~mol} \%$ of Dy doped BZT-BCNT ceramic system.

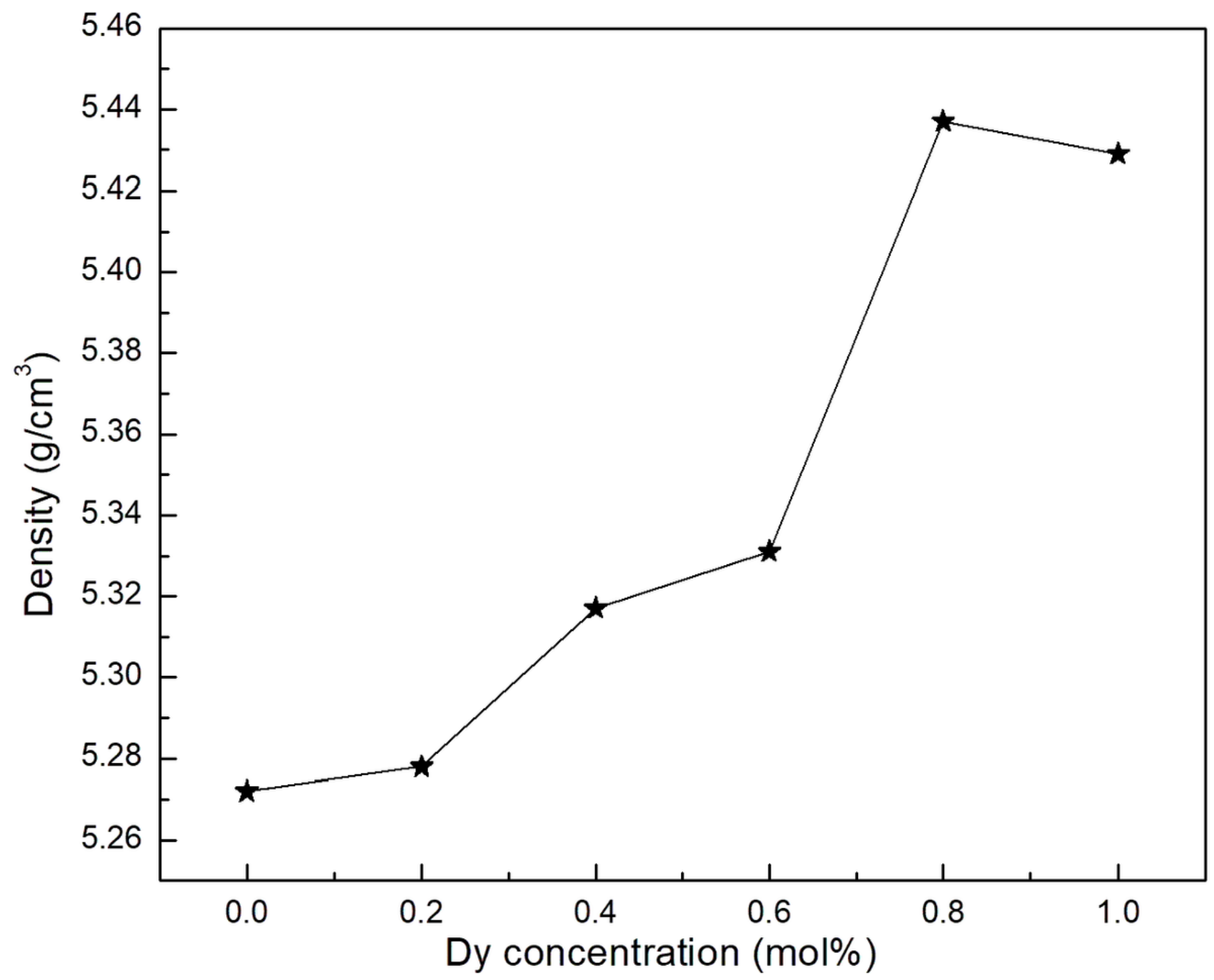

Figure 3 
Variation of apparent density as a function of Dy doped BZT-BCNT ceramic system.

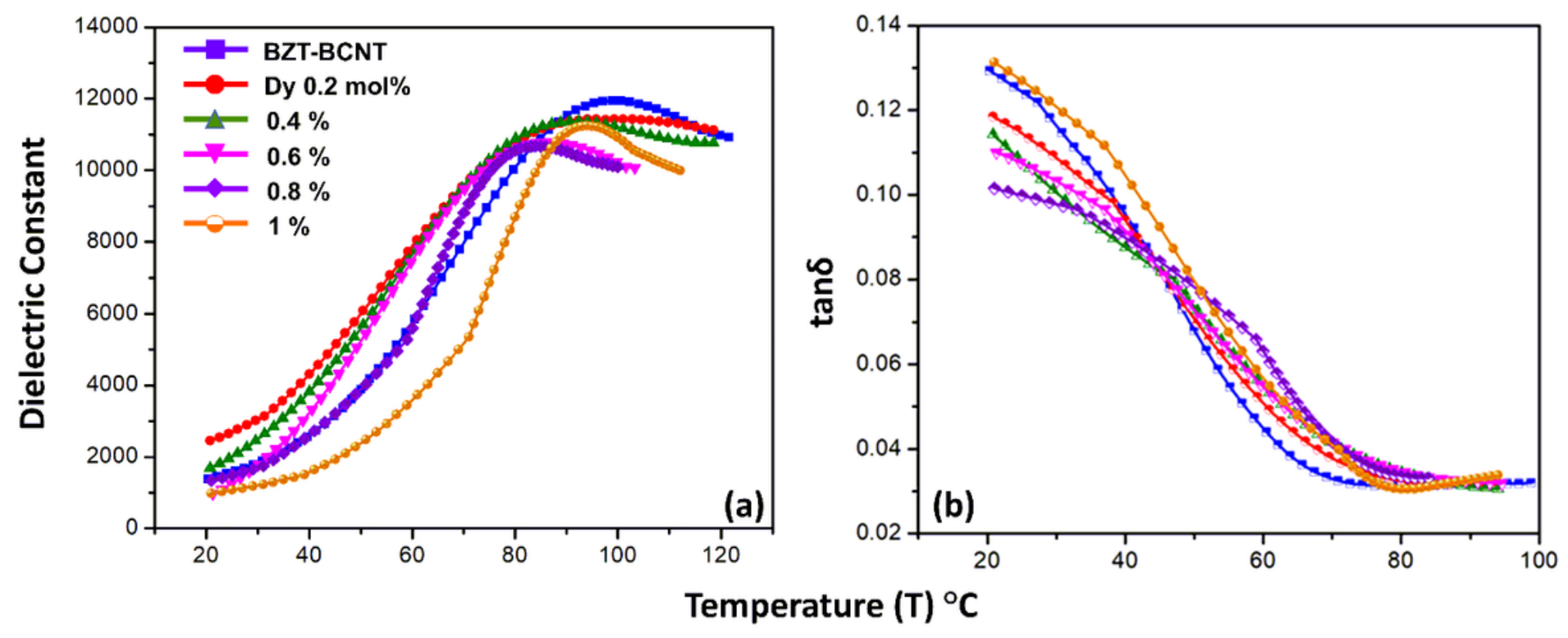

Figure 4

(a) Variation of dielectric constant (b) tand as a function of temperature for Dy doped BZT-BCNT ceramic system at $1 \mathrm{kHz}$. 


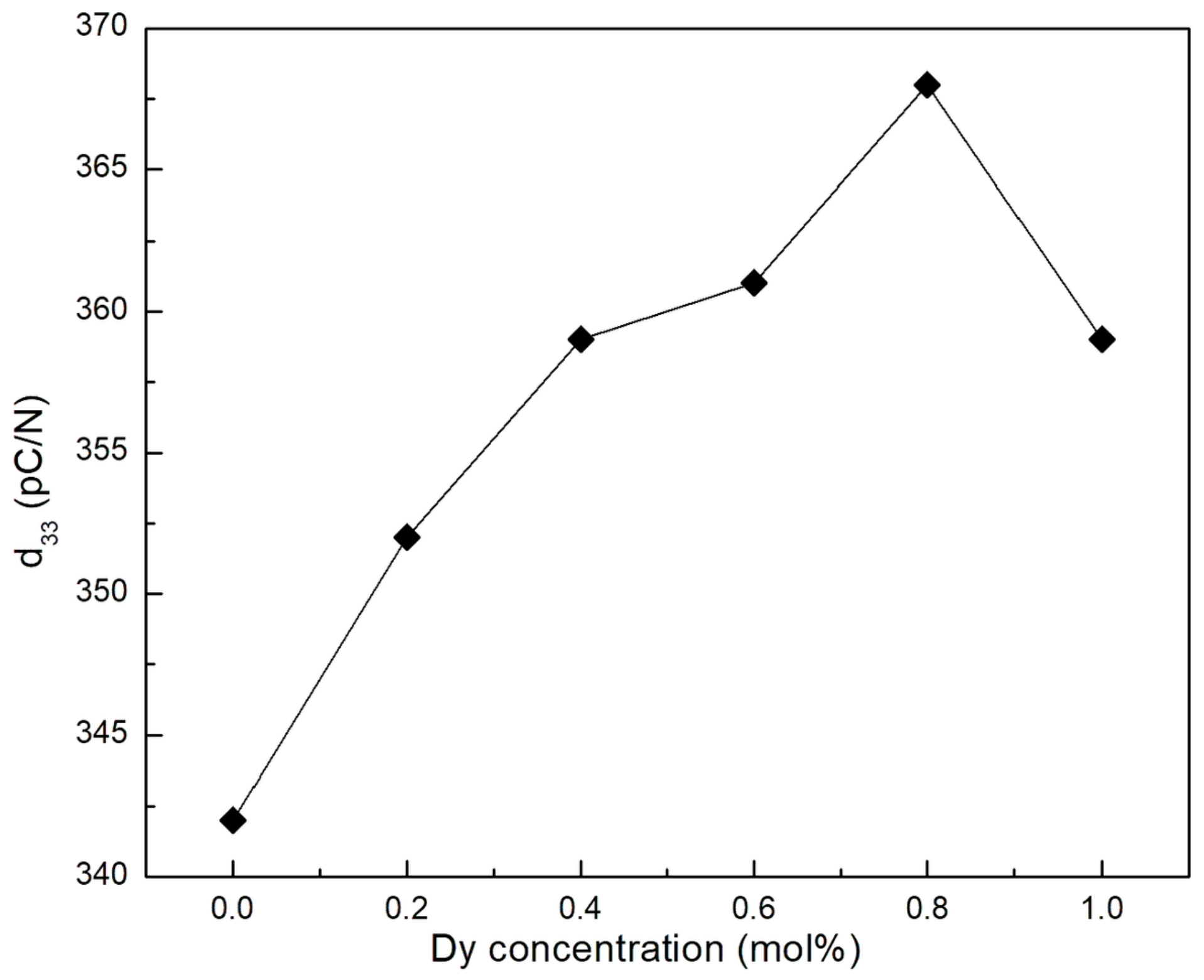

Figure 5

Variation of piezoelectric properties of Dy doped BZT-BCNT ceramic system. 